\title{
Relationship between growth speed and magnetic properties in
}

\section{Bi-2212/Ag textured composites}

Berdan ÖZKURT ${ }^{\mathrm{a},{ }^{*}}$, M. A. Madre ${ }^{\mathrm{b}}$, A. Sotelo ${ }^{\mathrm{b}}$, M.Eyyüphan Yakıncl, ${ }^{\mathrm{c}}$, Bekir Özçelik ${ }^{\mathrm{d}}$, J. C. Diez

${ }^{a}$ Department of Electronic and Computer Education, Faculty of Tarsus Technical Education, University of Mersin, Mersin/Turkey

b ICMA (CSIC-Universidad de Zaragoza). María de Luna, 3. 50018 Zaragoza. Spain.

${ }^{c}$ Department of Physics, Faculty of Sciences and Letters, İnönü University, 44069, Malatya Turkey

${ }^{d}$ Department of Physics,Faculty of Sciences and Letters, Çukurova University, 01330 Adana,Turkey

\section{Abstract}

In this paper, the magnetic properties of $\mathrm{Bi}_{2} \mathrm{Sr}_{2} \mathrm{CaCu}_{2} \mathrm{O}_{x} / 3$ wt.\%Ag textured composite materials prepared by a LFZ melting technique at different growth speeds $(5,15,30$ and $60 \mathrm{~mm} / \mathrm{h})$ are presented. X-ray diffraction patterns showed that in all cases the $\mathrm{Bi}-2212$ phase is the major one. The magnetization measurements have been carried out as a function of the magnetic field up to $10 \mathrm{kOe} . \mathrm{J}_{\mathrm{c}}$ values of the samples calculated using Bean's model indicate that the different growth speeds have significant effect on the $J_{C}$ values. It has been found that the maximum critical density $\mathrm{J}_{\mathrm{C}}, 4.42 \times 10^{5} \mathrm{~A} / \mathrm{cm}^{2}$ at $10 \mathrm{~K}$, has been obtained for the $15 \mathrm{~mm} / \mathrm{h}$ grown sample.

Keywords: Bi-2212, Ag, Grain growth, Magnetic properties, Critical current density $\left(J_{C}\right)$ 
* Corresponding author. Tel.: +90 324627 4804; fax: +90 3246274805

E-mail address: berdanozkurt@mersin.edu.tr 


\section{INTRODUCTION}

Since the discovery of superconductivity in the Bi-Sr-Cu-O system by Michel et al. [1] and the subsequent work reported by Maeda et al. [2] in $\mathrm{Bi}_{2} \mathrm{Sr}_{2} \mathrm{Ca}_{n-1} \mathrm{Cu}_{n} \mathrm{O}_{x}$ $(n=1,2,3)$ superconductor, a lot of studies have been performed in order to improve the physical properties of BSCCO system. The production of bulk BSCCO superconductor with a single phase (Bi-2223 or Bi2212) with high electrical transport capacity above liquid nitrogen temperature of $77 \mathrm{~K}$ is of great interest for practical applications like wires, tapes and thin films [3-6]. In particular, BSCCO materials have demonstrated that they are suitable for many transport applications when they are properly processed in order to obtain a good grain orientation [7-8]. Among the many preparation techniques used successfully to produce well textured materials [9-11], the directional growth from the melt by the Laser Floating Zone (LFZ) method has demonstrated to be a very useful technique for producing well textured BSCCO rods at high growth rates [12-15]. As it was previously reported, all type of LFZ grown materials possess very good grains alignment, with their $c$-axis quasi-perpendicular to the growth direction $[16,17]$. This high degree of texture leads to a very important increase of the transport properties, $J_{c}$, due to the reduction of the number of low-angle junctions [18].

However, the high-Tc superconductors have some problems like their fragility due to their ceramic nature. In order to improve their mechanical behaviour some attempts have been performed on BSCCO sintered materials. Most important research is the high ( 22wt.\%) silver $(\mathrm{Ag})$ addition into the BSCCO [19]. Further studies on laser grown materials have shown that the optimum Ag 
amount necessary to improve mechanical properties is much lower (1-3 wt.\%) than for sintered materials [20] due to their lower porosity.

Besides synthetic methods which already shown their effect on the properties of BSCCO materials [21,22], the growth rate also plays a very important role when preparing superconductor materials by LFZ technique. As a consequence, it is required to find out the optimum growth rate in order to obtain materials with very good grain alignment and carrying high critical current densities. This is of

critical importance for maximize the volume fraction of the high- $T_{C}$ phase and reduce the weak links between the superconducting grains.

In the present study, different growth rates have been used to produce textured $\mathrm{Bi}_{2} \mathrm{Sr}_{2} \mathrm{CaCu}_{2} \mathrm{O}_{x} / 3 w t . \% A g$ composites by the LFZ tecnique in order to determine the influence of growth speed on the microstructure and magnetic properties of the samples.

\section{EXPERIMENTAL}

Green ceramic cylindrical precursors, $\sim 120 \mathrm{~mm}$ long and $\sim 3 \mathrm{~mm}$ diameter, approximately, have been prepared from commercial $\mathrm{Bi}_{2.02} \mathrm{Sr}_{2.02} \mathrm{Ca}_{0.98} \mathrm{Cu}_{1.99} \mathrm{O}_{x} / 2.9 w t . \% A g$ composite powder precursors (Nexans SuperConductors $\mathrm{GmbH}$ ) by cold isostatic pressing with an applied pressure of $200 \mathrm{MPa}$ during 1 minute. The obtained green cylinders were subsequently used as feed in a directional solidification process which has been performed in a laser floating zone melting (LFZ) installation described elsewhere [23]. The bars have been processed using a continuous power Nd:YAG laser $(\lambda=1064$ 
$\mathrm{nm})$, under air, at growth rates of $5,15,30$, and $60 \mathrm{~mm} / \mathrm{h}$. In the process, the seed has been rotated clockwise at $3 \mathrm{rpm}$ in order to maintain the cylindrical geometry while the feed has been rotated anticlockwise at $15 \mathrm{rpm}$ to homogeneize the molten zone. Finally, after the growth process, the textured bars, about $\sim 150 \mathrm{~mm}$ length and $\sim 2 \mathrm{~mm}$ diameter, have shown to be very homogeneous dimensionally. These rods were then cut into several pieces with the adequate dimensions ( $\sim 3.5 \mathrm{~mm}$ long) for their magnetic characterization. The as-grown bars are composed of several non superconducting phases due to the inconguent melting of this compound. As a consequence, it is necessary to perform an annealing process to promote the superconducting phase formation [24]. This process consists in two steps, the first one at $860^{\circ} \mathrm{C}$ during $60 \mathrm{~h}$ to produce the $\mathrm{Bi}-2212$ phase, and the second one at $800^{\circ} \mathrm{C}$ for $12 \mathrm{~h}$ to adjust the oxygen content and maximize the electrical properties [25].

Phase determination has been performed on annealed samples using $\mathrm{X}$-ray powder diffraction measurements (Rigaku $D /$ max-B) with $2 \theta$ ranging between 10 and $60^{\circ}$. Microstructural characterization was made on polished longitudinal sections of the as-grown and annealed samples, in a scanning electron microscope (SEM, JEOL JSM 6400) equipped with an energy dispersive spectroscopy (EDX) system.

Magnetic measurements of all the samples were performed with a 7304 model Lake Shore VSM, after cooling the sample in zero magnetic field (ZFC), between $\pm 10 \mathrm{kOe}$ at three different temperatures: 10,15 , and $25 \mathrm{~K}$.

\section{RESULTS AND DISCUSSION}


Fig. 1 shows SEM images corresponding to longitudinal polished sections of samples grown at different rates before annealing. In these images, until five different phases can be identified, changing their proportion and orientation as a function of the growth rate. The different contrasts found in these micrographs have been associated to different phases by EDX analysis. The phase marked as \#1 (dark grey contrast) corresponds to the Bi-free primary solidification phase, with composition $(\mathrm{Sr}, \mathrm{Ca}) \mathrm{CuO}_{2}$. This phase appears in all the samples, except in the one grown at $5 \mathrm{~mm} / \mathrm{h}$, due to the low growth speed which can promote a higher reaction between secondary phases in the heat-affected zone after the solidification process. Other interesting feature observed for this phase is that it is initially well aligned with the rod axis (at $15 \mathrm{~mm} / \mathrm{h}$ growth rate), as expected from the flat solidification interface observed in the growth process [26], with an increased misalignment when the growth speed is raised. White phase (marked as \#2) shows a composition close to the ideal Bi-2201 stoichiometry. This phase's formation is promoted by its fast solidification kinetics from the Bi-enriched liquid, a process which follows initial nucleation of $\left(\mathrm{Ca}_{1-x} \mathrm{Sr}_{x}\right) \mathrm{CuO}_{2}$. Moreover, from the trends observed in Fig. 1 it can be deduced that the grain growth of this Bi-rich phase mainly follows the alignment of the primary solidified phase. Grey phase corresponds to the Bi-2212 phase (indicated by \#3). It can be identified in all samples, only in small proportions for the 15,30 and $60 \mathrm{~mm} / \mathrm{h}$ grown samples while it is the major one for the samples grown at $5 \mathrm{~mm} / \mathrm{h}$ due to the higher reaction produced between $(\mathrm{Sr}, \mathrm{Ca}) \mathrm{CuO}_{2}$ and $\mathrm{Bi}-2201$, leading to high $\mathrm{Bi}-2212$ phase content in these samples. Black contrast (marked as \#4) has been associated to $\mathrm{CaO}$. Finally, \#5 is associated with Ag particles, which can be also seen as grey contrasts but can be 
distinguished by their shapes, as they tend to be spherical ones at high growth speeds while for the $5 \mathrm{~mm} / \mathrm{h}$ grown samples, they are aligned with the ceramic grains, filling the holes between them.

Powder XRD patterns, performed on textured and annealed samples, are displayed in Fig. 2. From this graphic, it is clear that the major peaks correspond to the $\mathrm{Bi}-2212$ phase [27]. On the other hand, $\mathrm{Ag}$ is identified by the peak at around $39^{\circ}$ corresponding to the (111) plane [28]. These results confirm that the performed thermal treatment has been adequate for the $\mathrm{Bi}-$ 2212 phase formation, independently of the growth speed. This is a very important point when taking into account that the quaternary $\mathrm{Bi}_{2} \mathrm{O}_{3}-\mathrm{SrO}-\mathrm{CaO}-$ CuO system shows more than 20 stable phases [29]. Moreover, Ag addition modifies the phase relations of the $\mathrm{Bi}_{2} \mathrm{O}_{3}-\mathrm{SrO}-\mathrm{CaO}-\mathrm{CuO}$ system and its melting point [30] due to an eutectic reaction.

The microstructure of the annealed samples is presented in Fig. 3 where representative longitudinal polished sections for each growth speed are shown. From this figure, it is clear that $\mathrm{Bi}-2212$ (\#1, grey contrast) is the major phase in all samples, confirming the XRD data discussed previously. Only small amounts of secondary phases are observed, corresponding to Bi-2201 (\#2, white), (Sr,Ca)-Cu-O phases (\#3, dark grey), and $\mathrm{CaO}$ (\#4, black). Ag is also present (\#5, grey) in all the samples, even if it is difficult to observe it at this magnification level, filling the intergranular holes between the superconducting grains, as reported previously [31]. Moreover, the micrographs show the same trends observed in the as-grown materials, misalignment of grains is increased when the growth speed is raised. 
Fig. 4 shows the magnetic hysteresis curves, obtained at $10 \mathrm{~K}$, for the samples grown at $5,15,30$, and $60 \mathrm{~mm} / \mathrm{h}$. The general behaviour of hysteresis loops indicates that the magnetic behaviour of the samples strongly depends on the growth speed. The magnitude of the magnetization follows a decreasing trend when growth speeds increases, except for the sample grown at $5 \mathrm{~mm} / \mathrm{h}$ which is lower than the obtained for the $15 \mathrm{~mm} / \mathrm{h}$. This result agrees with previously published works in this system [31] where samples grown at $5 \mathrm{~mm} / \mathrm{h}$ have shown many intergranular cracks after annealing (they can also be observed in Fig. 3a) which cause negative effects in the intergrain connectivity. As a consequence, the magnetization values for the $15 \mathrm{~mm} / \mathrm{h}$ grown samples are higher than the obtained for samples grown at $5 \mathrm{~mm} / \mathrm{h}$. Moreover, the superconducting properties of the $15 \mathrm{~mm} / \mathrm{h}$ grown samples are much better than those obtained for samples grown at higher rates since its hysteresis loop is much larger, leading to higher calculated critical current densities. This decrease in the magnitudes of hysteresis loops with increasing growth speeds also reflects the changes produced in the effect of flux pinning centers. Figs. 5 and 6 also show the magnetic hysteresis curves of all the samples performed at 15 and $25 \mathrm{~K}$. When comparing the curves obtained at the different temperatures, it can be clearly seen that, independently of temperature, the observed behaviour is similar to that explained previously at $10 \mathrm{~K}$. When comparing the hysteresis loops for the same material at different temperatures (see Figs. 4, 5, and 6), it can be observed that the loops are narrower with increasing temperature. Moreover, their symmetrical shape indicates that the magnetization behaviour at low fields is dominated by bulk pinning rather than by surface and/or geometrical barriers [32]. As can be seen from these figures, 
due to the pinning effects and the large volume of the superconducting regions, the magnetic field penetration becomes difficult below $10 \mathrm{~K}$, but the applied fields begin to significantly penetrate into the samples at higher temperatures due to the decrease of the superconducting regions and the weakening of grain connectivity with increasing temperature. This is probably the reason for the large decreases appearing in the width of the magnetic hysteresis loops above $10 \mathrm{~K}[33]$.

The $J_{C}$ values of the samples were calculated, from the hysteresis loops, for the three different temperatures, 10,15 and $25 \mathrm{~K}$, using the Bean's model [34]:

$$
\mathrm{J}_{\mathrm{C}}=30 \frac{\Delta M}{d}
$$

where $J_{C}$ is the magnetization current density in ampéres per square centimeter of a sample. $\Delta M=M_{+}-M_{\text {- }}$ is measured in electromagnetic units per cubic centimeter, and $d$ is the thickness of sample.

Figures 7, 8 and 9 show the calculated critical current densities for all the samples, as a function of the applied field, at the three mentioned temperatures. As it can be clearly seen in these figures, $J_{C}$ calcultions indicates that the 15 $\mathrm{mm} / \mathrm{h}$ grown sample possesses the highest $\mathrm{J}_{\mathrm{C}}$ values, independently of the measured temperature. Moreover, comparing the values obtained for each material at different temperatures, it is evident that $J_{C}$ values significantly decrease with the magnetic field, temperature and growth speeds. The maximum calculated critical current density has been $4.42 \times 10^{5} \mathrm{~A} / \mathrm{cm}^{2}$ at $10 \mathrm{~K}$ and 0.0 Oe applied external field, for the $15 \mathrm{~mm} / \mathrm{h}$ sample. The decrease of $\mathrm{J}_{\mathrm{C}}$ can be explained with the same arguments used to explain the hysteresis loops evolution as a function of the measured temperature and growth speed. 
In general, higher values of $J_{C}$ have been observed while weak magnetic field dependence was still obtained at $T>10 \mathrm{~K}$. This is expected because the magnetization curve of the sample forms a loop that indicates the presence of the pinning centers on the surface of the materials. It is also well-known that in the high- $T_{c}$ superconducting materials, non-superconducting impurity phases are highly effective in the flux-pinning mechanism when they have adequate sizes. Thus, a higher critical current density with small amount of nonsuperconducting phases is possibly the result of pinning mechanism in the superconductor [34].

\section{CONCLUSIONS}

$\mathrm{Bi}_{2} \mathrm{Sr}_{2} \mathrm{CaCu}_{2} \mathrm{O}_{x} / 3 \mathrm{wt} . \%$ Ag polycristalline materials have been successfully textured using the LFZ technique. The effect of different growth speeds on the magnetic properties of these materials have shown a significant enhancement of $J_{C}$ when the growth speed is decreased, except in the case of the $5 \mathrm{~mm} / \mathrm{h}$ grown samples. The best $J_{C}$ results have been obtained for samples grown at $15 \mathrm{~mm} / \mathrm{h}$ and measured at $10 \mathrm{~K}$ and $0.0 \mathrm{Oe}\left(\sim 4.4 \times 10^{5} \mathrm{~A} / \mathrm{cm}^{2}\right)$. The use of higher or lower growth speeds decreases $\mathrm{J}_{\mathrm{C}}$ values, in the first case due to the increase of misalignement of the superconducting grains. In the second case, it is explained taken into account the observed crack formation between the superconducting grains.

\section{References}

[1] Michel C., Hervieu M., Borel M., Grandin A., Deslandes F., Provost J., Raveau B., Z.: Phys. B 68, 421 (1987) 
[2] Maeda, H., Tanaka, Y., Fukutomi, M., Asano, T.: Jpn. J. Appl. Phys. 27, L 209 (1988)

[3] Abou-Aly, A.I., Abdel Gawad, M.M.H., Awad, R., G-Eldeen, I.: J. Supercond. Nov. Magn. 24, 2077 (2011)

[4] Cyrot, M., Pavuna, D.: Introduction to Superconductivity and High-Tc Materials. Word Scientific, Singapore 249, (1995)

[5] Chen, M., Donzel, L., Lakner, M., Paul, W.: J. Eur. Ceram. Soc. 24, 1815 (2004)

[6] Huang, Y. B., de la Fuente, G. F., Sotelo, A., Ruiz, M. T., Larrea, A., Angurel, L. A., Navarro, R.: Solid State lonics 63-65, 889 (1993)

[7] Hermann, P. F.: Handbook of Applied Superconductivity. IOP Publishing, Bristol (1998)

[8] Noe, M., Juengst, K. P., Werfel, F.N., Elschner, S., Bock, J., Breuer, F., Kreutz, R.: IEEE Trans. Appl. Supercond. 13, 1976 (2003)

[9] Garnier, V., Caillard, R., Sotelo, A., Desgardin, G.: Physica C 319, 197 (1999)

[10] Martin-Gonzalez, M. S., Garcia-Jaca, J., Moran, E., Alario-Franco, M. A.: J. Mater. Res. 14, 3497 (1999)

[11] Maeda, H., Ohya, K., Sato, M., Chen, W. P., Watanabe, K., Motokawa, M., Matsumoto, A., Kumakura, H., Schwartz, J.: Physica C 382, 33 (2002)

[12] Feigelson, R. S., Gazit, D., Fork, D. K., Geballe, T. H.: Science 240, 1642 (1988)

[13] Sotelo, A., Madre, M. A., Diez, J. C., Rasekh, Sh., Angurel, L. A., Martınez, E.: Supercond. Sci. Technol. 22, 034012 (2009) 
[14] Mora, M., Sotelo, A., Amaveda, H., Madre, M.A., Diez, J. C., Capel, F., López-Cepero, J.M.: J. Eur. Ceram. Soc. 27, 3959 (2007)

[15] Mora, M. Sotelo, A., Amaveda, H., Madre, M. A., Diez, J. C., Angurel, L. A., de la Fuente, G. F.: Bol. Soc. Esp. Ceram. V. 44, 199 (2005)

[16] de la Fuente, G. F., Ruiz, M. T., Sotelo, A., Larrea, A., Navarro, R.: Mater. Sci. Eng. A 173, 201 (1993)

[17] Sotelo, A., Guilmeau, E., Madre, M. A., Marinel, S., Diez, J. C., Prevel, M.:

J. Eur. Ceram. Soc. 27, 3697 (2007)

[18] Shi, D.: High Temperature Superconducting Materials Science and Engineering. Pergamon Press, Oxford (1995)

[19] Salazar, A., Pastor, J. Y., Llorca, J.: Physica C 385, 404 (2003)

[20] Sotelo, A., Mora, M., Madre, M. A., Diez, J. C., Angurel, L. A., de la Fuente, G. F.: J. Eur. Ceram. Soc. 25, 2947 (2005)

[21] Sotelo, A., Szillat, H., Majewski, P., Aldinger, F.: Supercond. Sci. Technol. $10,717(1997)$

[22] Sotelo, A., Peña, J. I., Angurel, L. A., Diez, J. C., Ruiz, M. T., de la Fuente, G. F., Navarro, R.: J. Mater. Sci. 32, 5679 (1997)

[23] Sotelo, A., Rasekh, Sh., Madre, M.A., Diez, J. C.: J. Supercond. Nov. Magn. 24, 19 (2011)

[24] Sotelo, A., Mora, M. A., Amaveda, H., Diez, J. C., Angurel, L. A., Mayoral, M. C.: Bol. Soc. Esp. Ceram. V. 45, 228 (2006)

[25] Carrasco, M. F., Costa, F. M., Silva, R. F., Gimeno, F., Sotelo, A., Mora, M., Diez, J. C., Angurel, L. A.: Physica C 415, 163 (2004)

[26] de la Fuente, G. F., Diez, J. C., Angurel, L. A., Peña, J. I., Sotelo, A., Navarro, R.: Adv. Mater. 7, 853 (1995) 
[27] Vanderah, T. A.: Chemistry of superconductor materials. Noyes publications. New Jersey (1992)

[28] Lingun, L., Bassett, W. A.: J. Appl. Phys. 44, 1475 (1973)

[29] Majewski, P.: Supercond. Sci. Technol. 10, 453 (1997)

[30] Majewski, P., Sotelo, A., Szillat, H., Kaesche, S., Aldinger, F.: Physica C 275, 47 (1997)

[31] Özkurt, B., Madre, M. A., Sotelo, A., Yakıncı, M.E., Özçelik, B.:

J. Supercond. Novel Magnetism 25, 799 (2012)

[32] Chevalier, B., Lepine, B., Lalerzin, A., Darriet, J., Eournau, J. and Tarascon, J.M.: Mater. Sci. Eng. B 2, 277 (1989)

[33] Yazıcı, D., Özçelik, B., Yakıncı, M. E.: J. Low Temp. Phys. 163, 370-379 (2011)

[34] Bean, C. P.: Phys. Rev.Lett. 8, 250 (1962). 


\section{Figure captions}

Figure 1. SEM micrographs of polished longitudinal sections of the Bi-2212/3 wt.\%Ag textured materials before annealing: (a) 5; (b) 15; (c) 30; and (d) $60 \mathrm{~mm} / \mathrm{h}$. The numbers indicate the different phases: 1) $\left.(\mathrm{Sr}, \mathrm{Ca}) \mathrm{CuO}_{2} ; 2\right) \mathrm{Bi}-$ 2201; 3) Bi-2212; 4); $\mathrm{CaO}$; and 5) Ag.

Figure 2. Powder XRD patterns of the Bi-2212/3 wt.\%Ag textured ceramic composites at different growth speeds (a) 5; (b) 15; (c) 30; and (d) $60 \mathrm{~mm} / \mathrm{h}$. Bi2212 diffraction peaks are identified by the corresponding crystallographic planes. Ag (111) peak is indicated by a \#.

Figure 3. SEM micrographs of polished longitudinal sections of the Bi-2212/3 wt.\%Ag textured materials after annealing: (a) 5; (b) 15; (c) 30 ; and (d) $60 \mathrm{~mm} / \mathrm{h}$. The numbers indicate the different identified phases: 1) Bi-2212; 2) Bi-2201; 3) (Sr,Ca)-Cu-O; 4); $\mathrm{CaO}$; and 5) Ag.

Figure 4. Magnetization hysteresis curves measured at $10 \mathrm{~K}$, between $\pm 1 \mathrm{~T}$ external applied fields, for all the different growth speeds.

Figure 5. Magnetization hysteresis curves measured at $15 \mathrm{~K}$, between $\pm 1 \mathrm{~T}$ external applied fields, for all the different growth speeds.

Figure 6. Magnetization hysteresis curves measured at $25 \mathrm{~K}$, between $\pm 1 \mathrm{~T}$ external applied fields, for all the different growth speeds.

Figure 7. Calculated critical current densities of the samples at $10 \mathrm{~K}$ as a function of the applied field and the growth speed.

Figure 8. Calculated critical current densities of the samples at $15 \mathrm{~K}$ as a function of the applied field and the growth speed. 
Figure 9. Calculated critical current densities of the samples at $25 \mathrm{~K}$ as a function of the applied field and the growth speed. 
Figure 1
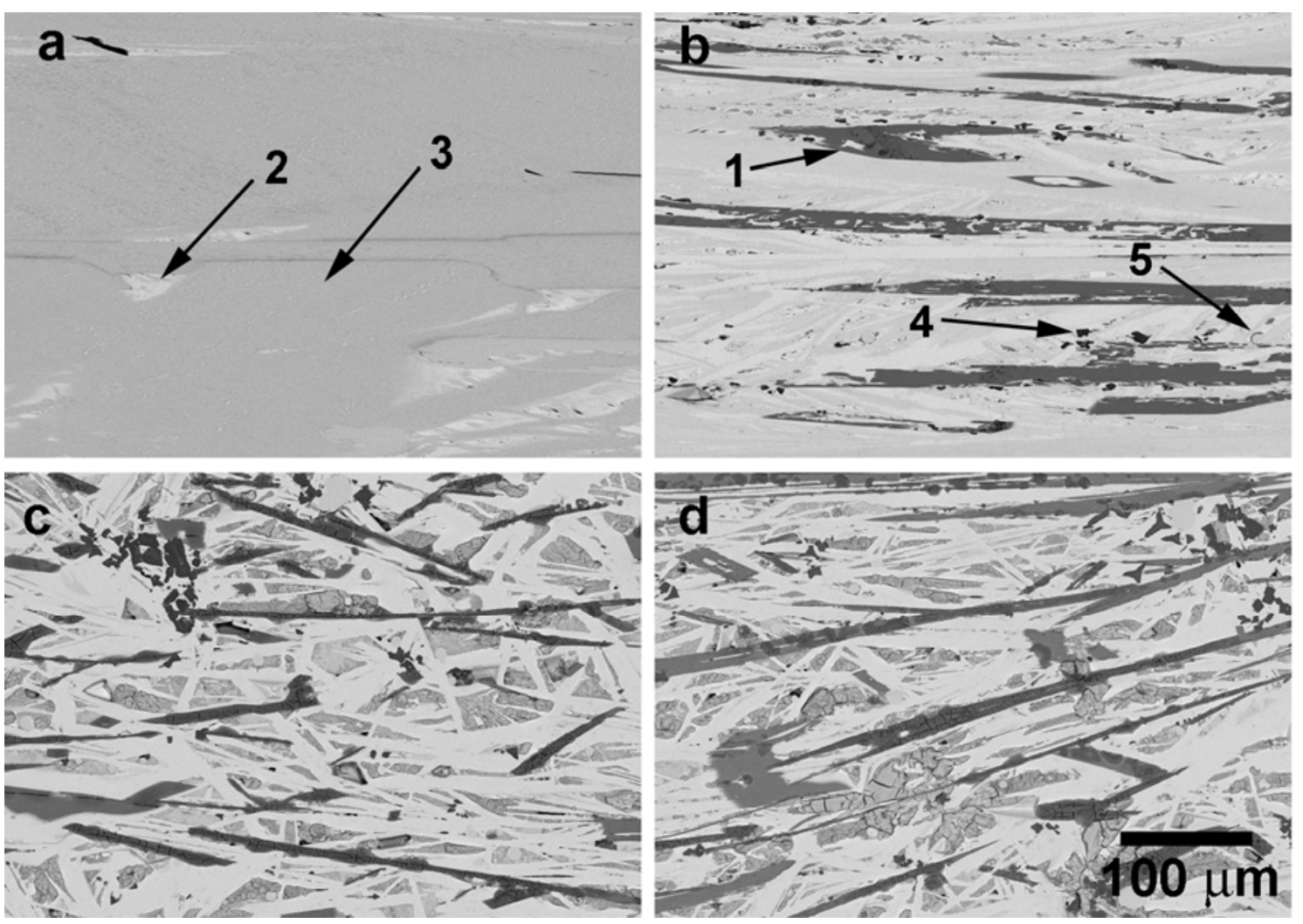
Figure 2

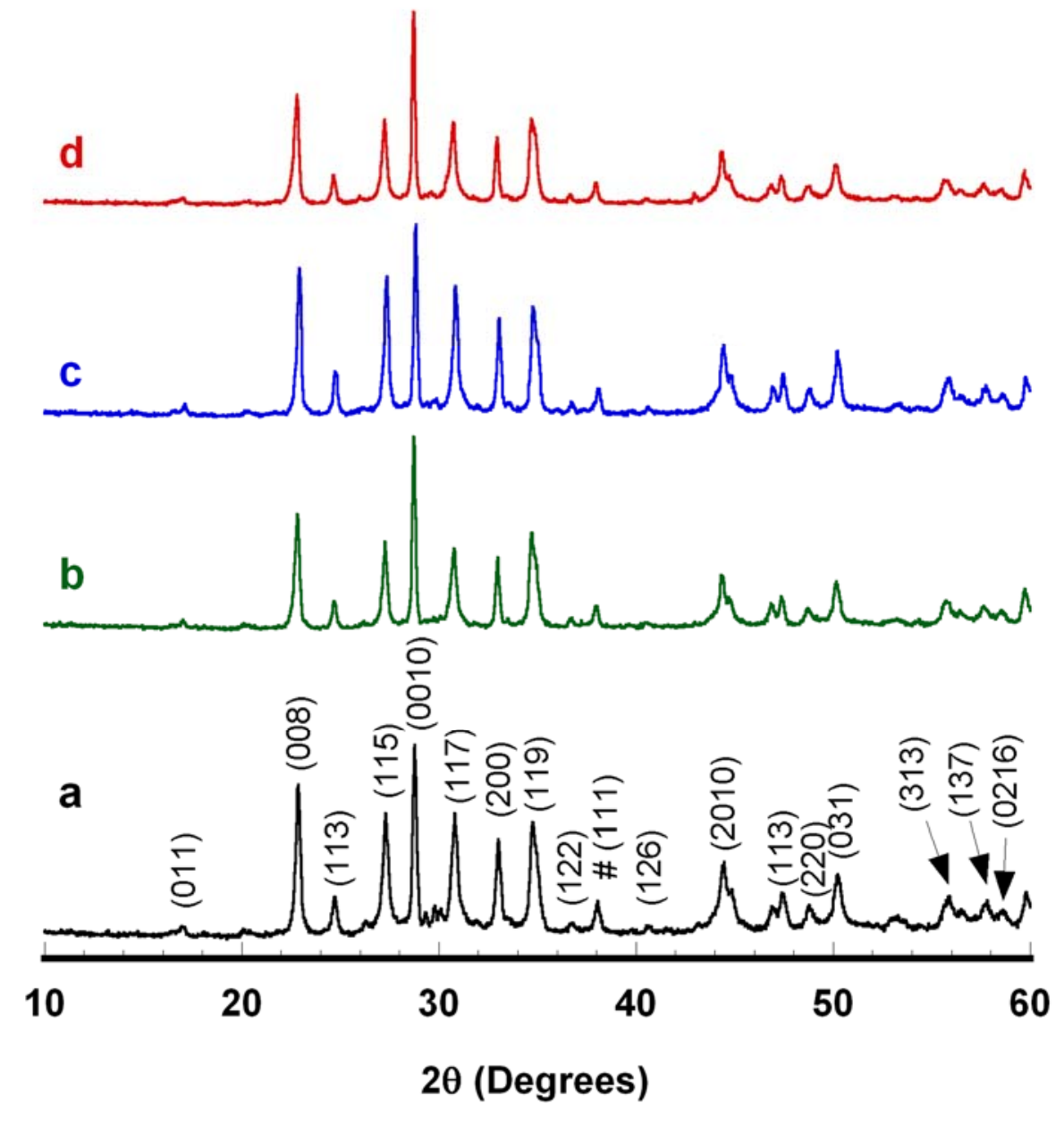


Figure 3
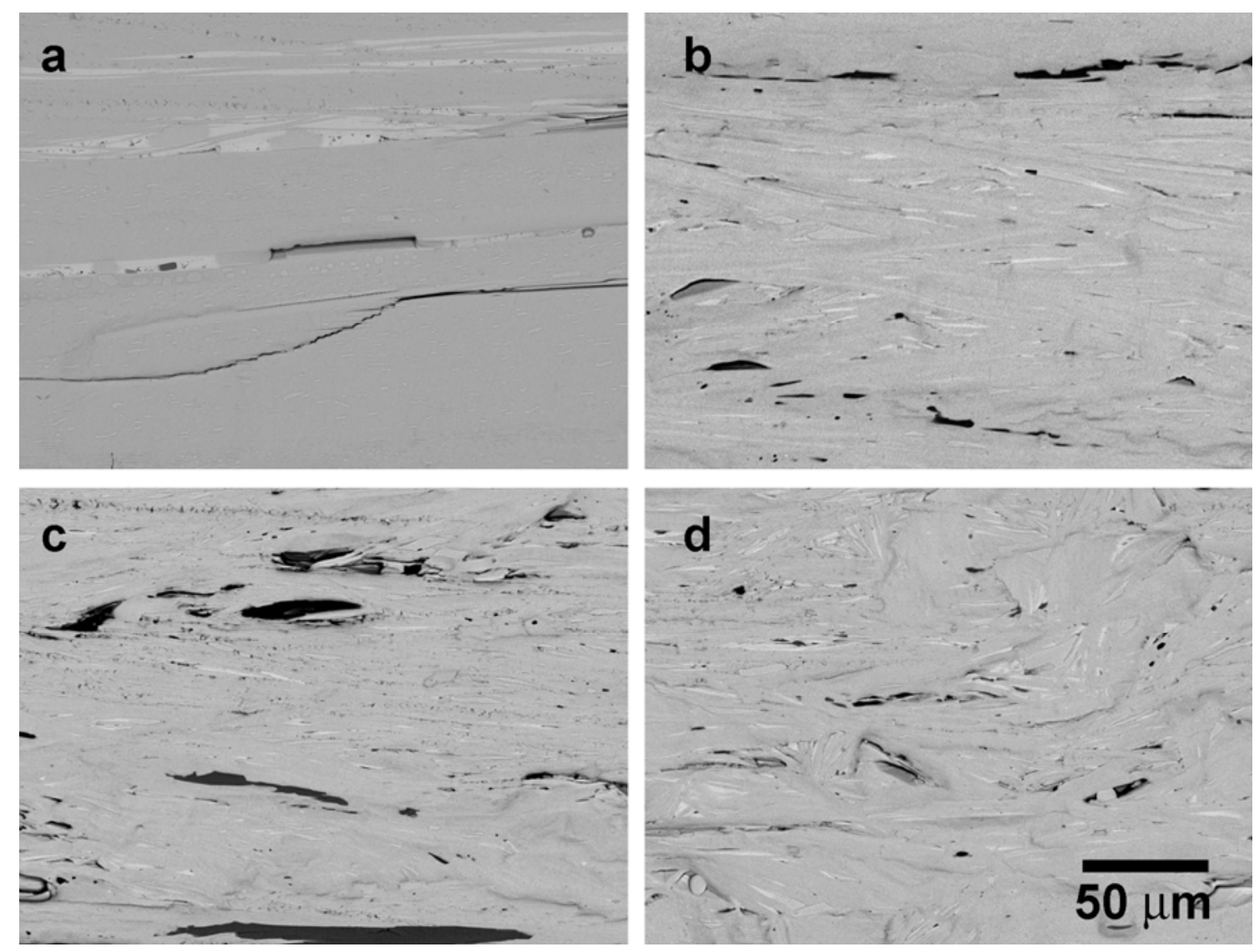
Figure 4

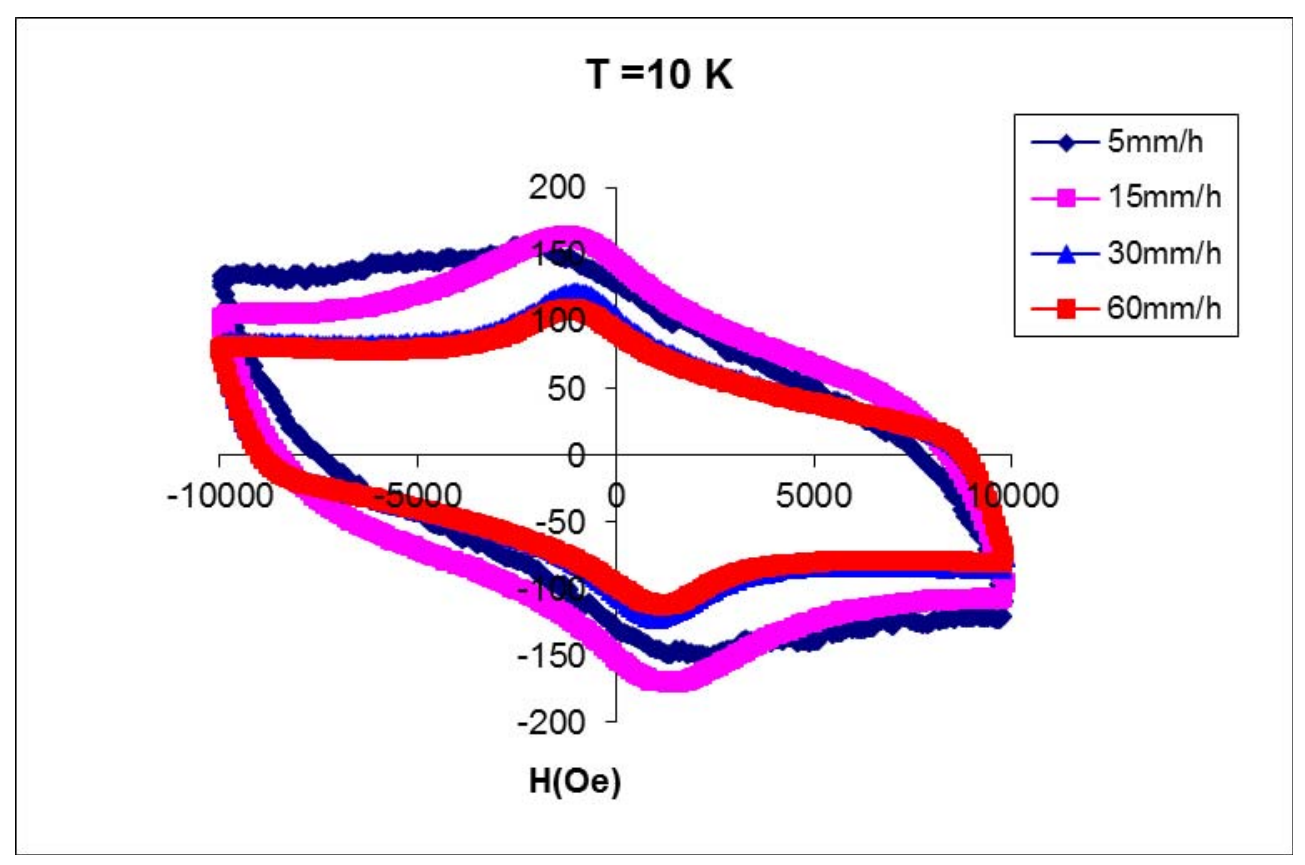


Figure 5

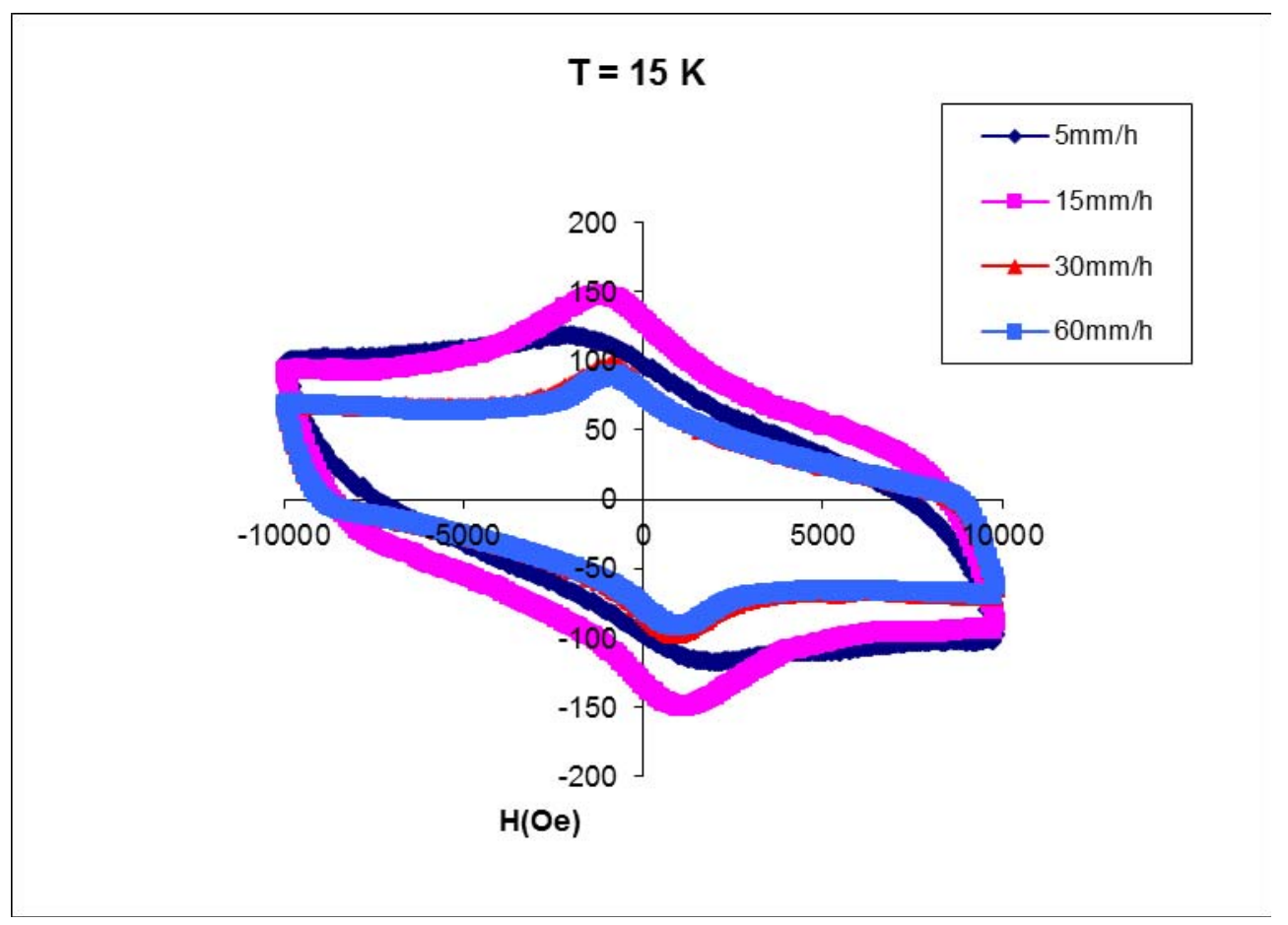


Figure 6

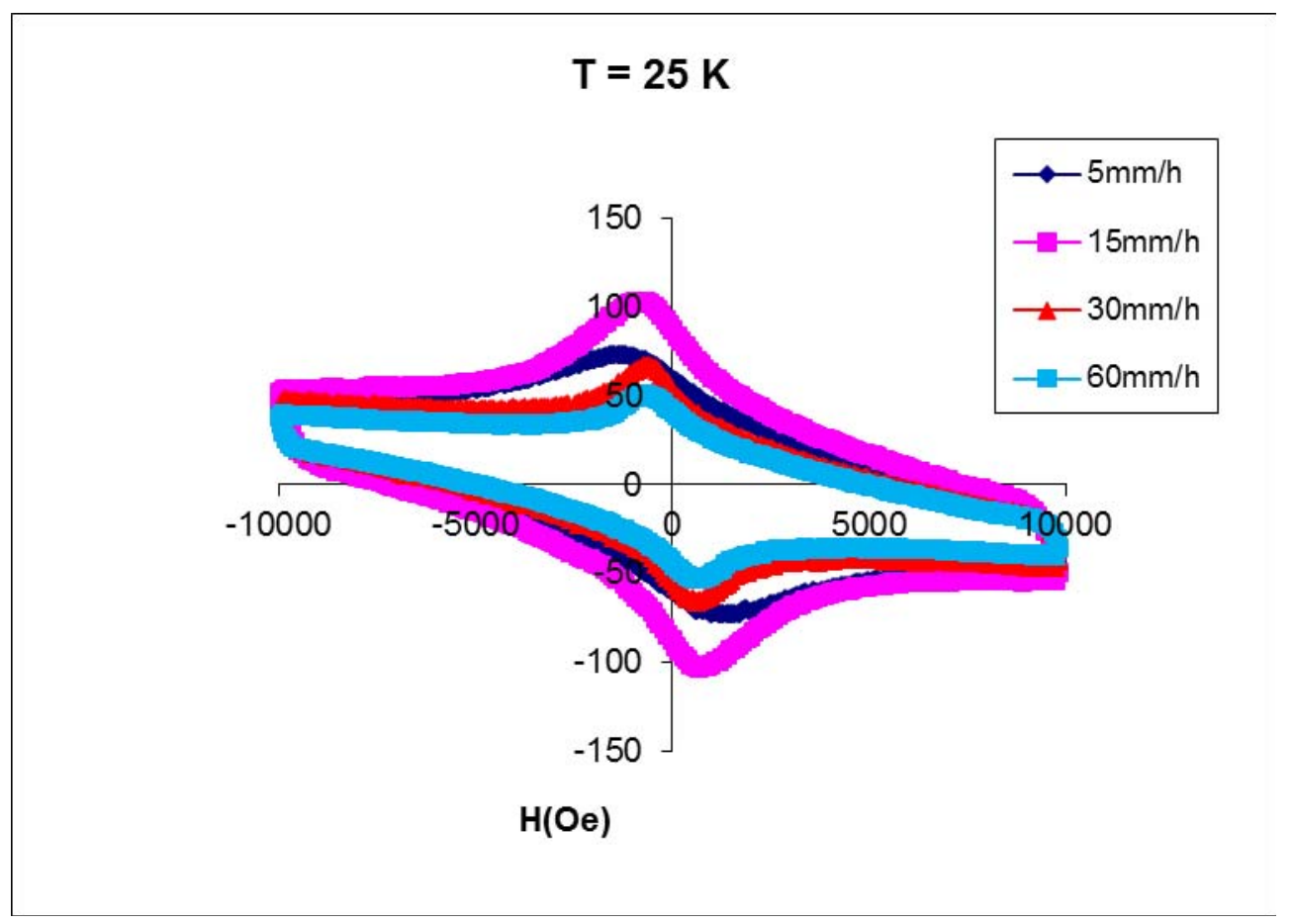


Figure 7

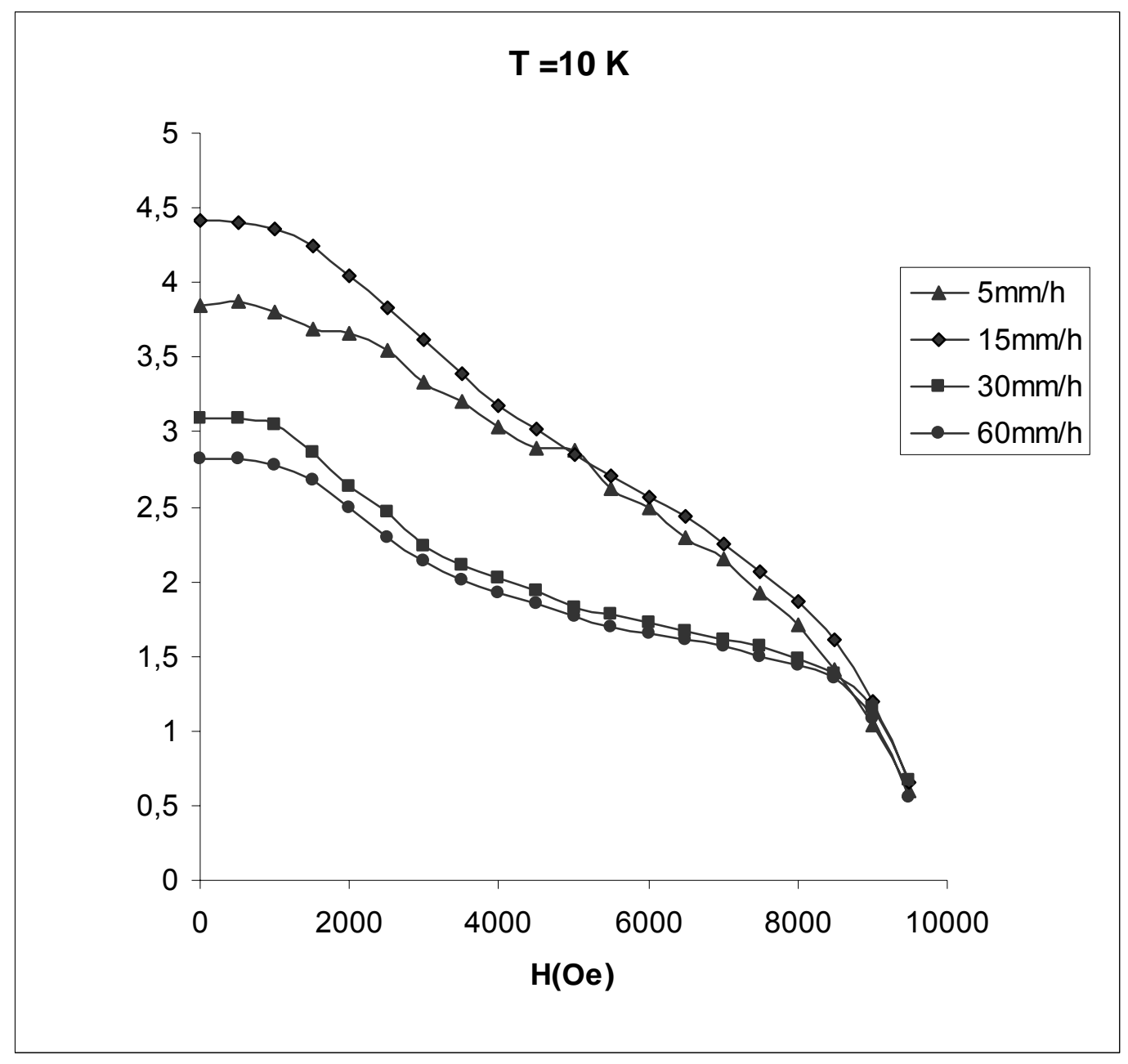


Figure 8

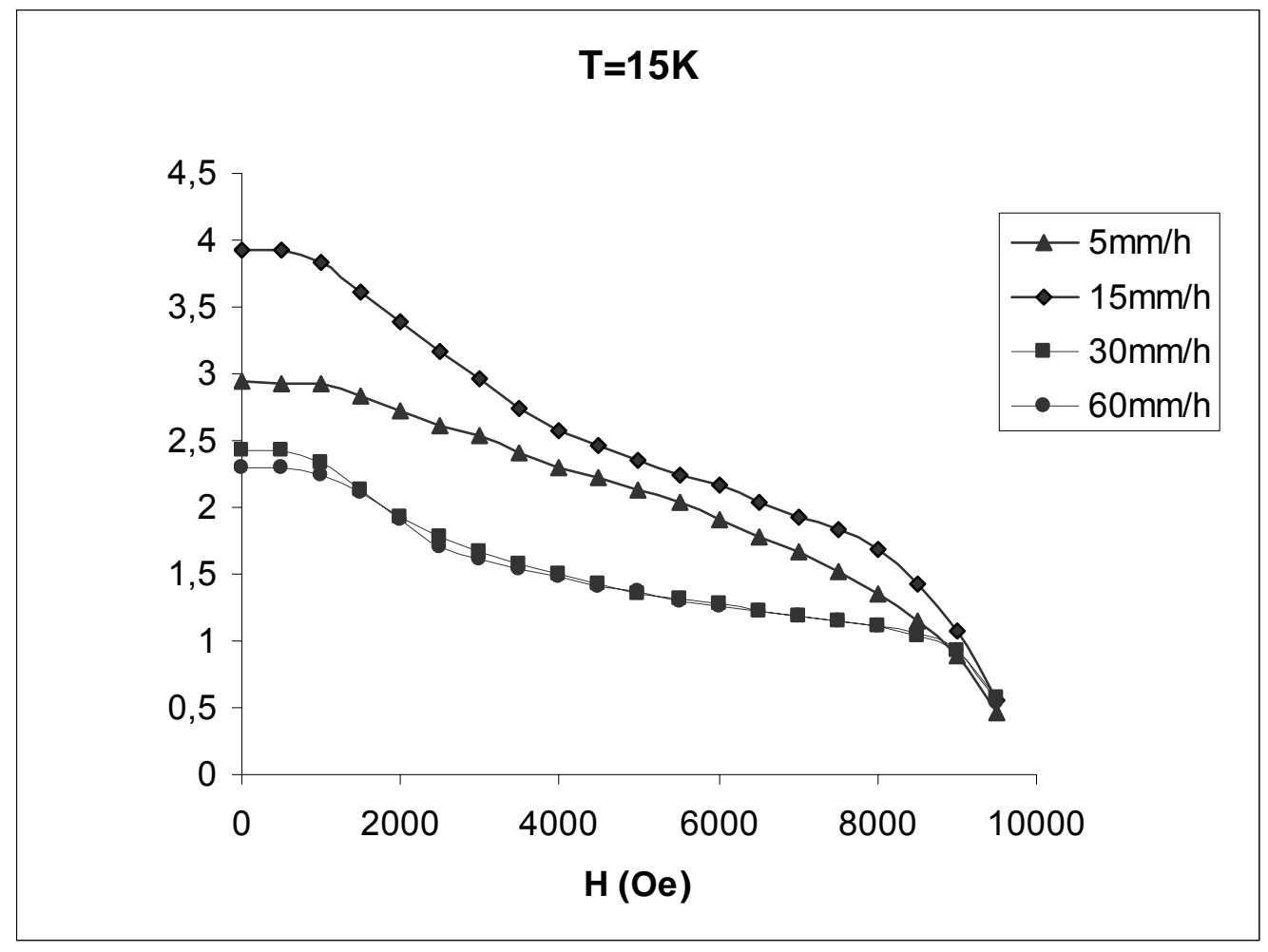


Figure 9

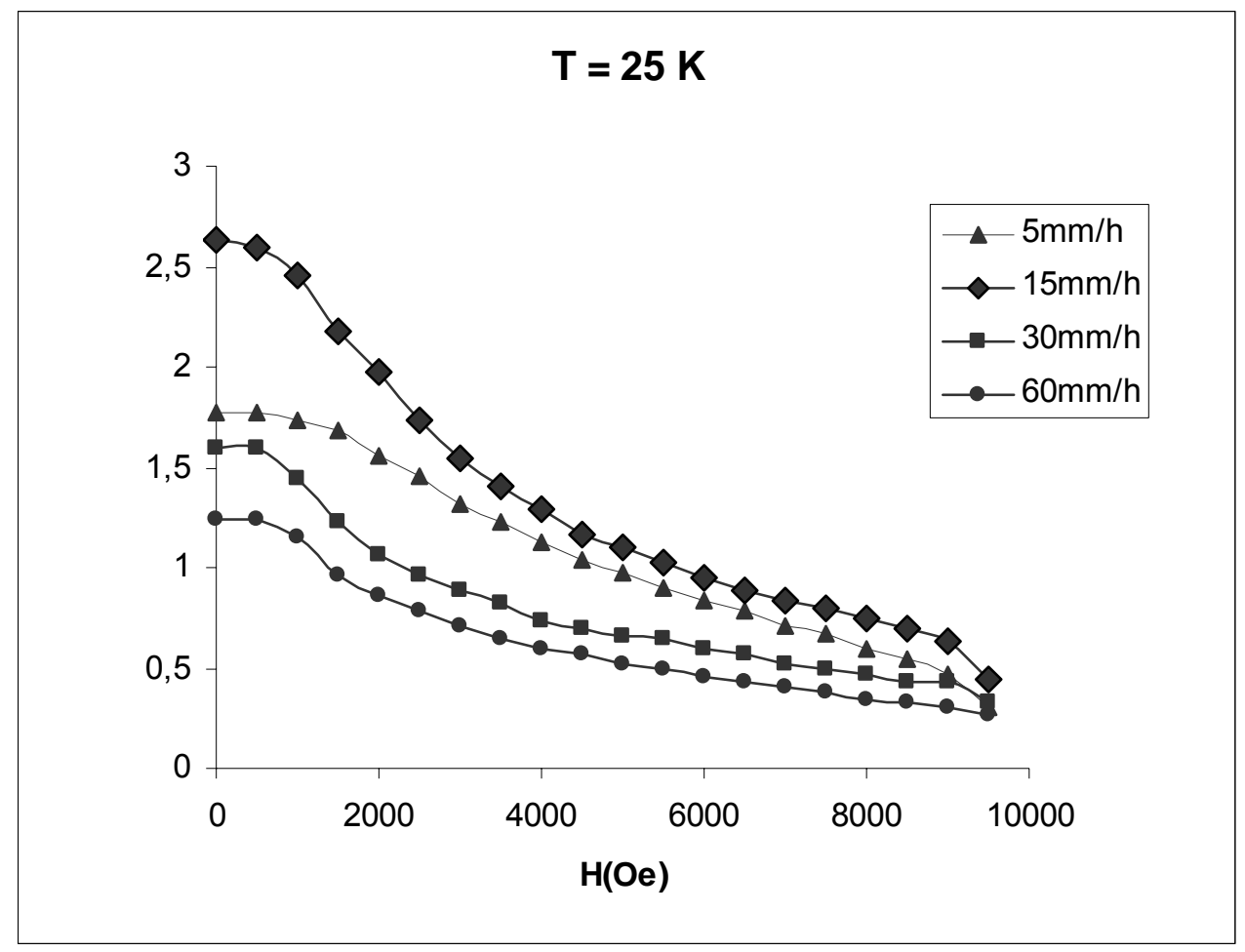

